\title{
Enhancing Curriculum in a First-Year Introduction to Engineering Course to Assist Students in Choice of Major
}

\section{Dr. J. C. McNeil, University of Louisville}

Jacqueline McNeil is an Assistant Professor for the Department of Engineering Fundamentals at University of Louisville. She is investigating nontraditional student pathways in engineering. She finished her Ph. D. in December 2014, titled, "Engineering Faculty Views of Teaching Quality, Accreditation, and Institutional Climate and How They Influence Teaching Practices." Her research is focused on engineering faculty perceptions of quality and on nontraditional students in engineering. McNeil received her master's degree in Engineering Management from South Dakota School of Mines and Technology (SDSMT) in August 2011. She was a mentor and tutor for American Indian students at SDSMT during that time. She worked as a mining engineer in industry between graduating with her engineering undergraduate degree and starting her graduate studies. Contact her at j.mcneil@ louisville.edu

\section{Dr. Angela Thompson P.E., University of Louisville}

Dr. Angela Thompson is an Assistant Professor in the Department of Engineering Fundamentals at the University of Louisville. Dr. Thompson received her PhD in Mechanical Engineering from the University of Louisville. Her research interests are in biomechanics and engineering education, particularly related to critical thinking instruction. 


\title{
Enhancing Curriculum in a First-Year Introduction to Engineering Course to Assist Students in Choice of Major
}

\begin{abstract}
This research paper describes a series of activities that were implemented in a first-year Introduction to Engineering course to assist students in their choice of major. Many students switch engineering majors after their first year causing possible delays in graduation, excessive credits that end up not being used towards any degree, and wasted time and money associated with the class, book fees, and energy. We want students to make the best decision possible during their first year to avoid the unnecessary headache from having to switch majors in the middle of their degree program.
\end{abstract}

In order to help students make an informed choice about their major, the various engineering disciplines are discussed as part of the Introduction to Engineering course, a required course for all first-year engineering students. This has typically been accomplished through department presentations or seminars in which faculty from the various engineering departments give presentations to students. Our department is currently restructuring the course and sought to provide additional opportunities for students to interact with engineers in the various disciplines. Thus in Fall 2015, a series of company panels introducing students to engineering employers was added to the course (in addition to the department presentations). The goal of this research was to determine the impact of course activities (department presentations and company panels) on students' decisions regarding choice of major.

Two surveys were given to students: one following the department presentations and the other following the company panels. Results indicate that both activities, department presentations and company panels, were viewed positively by a majority of students. The department presentations (given early in the semester) particularly helped students make a decision about their major. Though company panels appeared less effective (a lower percentage of students felt these helped them decide on a major), the decrease could simply be due to the fact that these came later in the semester and a majority of students had already made up their mind about which major to pursue. Additionally, students' confidence increased in their choice of major suggesting that the company panels were effective. Survey comments provided specific feedback regarding which aspects of the activities students found most helpful and insight into changes that might improve the activities in future semesters.

\subsection{Introduction}

At our university, approximately $30 \%$ of students in engineering programs switch majors within their first year. Students that switch engineering majors after their first year often have to make up classes for that specific engineering major that were not the same as the students' previous major. This causes delays in graduation, excessive credits that end up not being used towards any degree, and wasted time and money associated with the class, book fees, and energy. We want students to make the best decision possible during their first year to avoid the unnecessary headache from having to switch majors in the middle of their degree program. Engineering, in particular, does not have clear pathways for transfer students because each course builds on the 
next, and almost all engineering programs have students start this class building process as freshman. This system makes it nearly impossible for students to transfer in as juniors or seniors and expect to graduate in one or two years. This compounds the problem for students that are switching their major, and highlights the importance of identifying activities that help students make an informed decision in their freshman year.

In order to help students make an informed choice about their major, the various engineering disciplines are discussed as part of the Introduction to Engineering course, a required course for all first-year engineering students. This is a large enrollment course (in the fall of 2015, there were 615 students in 18 sections) taught by two faculty and four teaching assistants. Introductions to the various disciplines is one of many topics presented in the course; other course topics include critical thinking, team building and communication, ethics, professionalism, and an introduction to engineering design.

Similar to first-year courses at other engineering schools ${ }^{1-3}$, the various disciplines have typically been presented to the students through department seminars in which faculty from each of the engineering departments give presentations to students. Our department is currently re-vamping the Introduction to Engineering course and has added some activities to see if it would help students decide their choice of major within the first semester or year rather than later in the student's engineering program. In addition to department presentations, 24 engineering companies were invited to the school through a unique collaboration with the Engineering Co-op and Career Development Office. Company representatives spoke to the students as part of a series of company panels to provide a professional perspective on the various engineering disciplines.

We suspect that providing students information and interaction with engineers in various disciplines early in their curriculum will help them make more informed decisions about which engineering discipline to choose as a major and thus reduce the chance of switching later on. Thus, the purpose of this study was to determine whether activities in the Introduction to Engineering course, specifically the department presentations and company panels, were effective in helping students decide on a major.

\subsection{Literature Review}

The researchers looked at the research on choice of major and how students decide between engineering majors. There are not many studies on why students choose a specific engineering major.

Our work is on how exposure to company panels (engineering co-op employers) and department presentations affect the student's decision to stay in engineering and which engineering major they choose. A qualitative study of nonpersisters in engineering showed that individual factors and institutional factors influenced the students' decision to leave engineering. ${ }^{4}$ Individual factors included: failure to integrate into engineering culture, disappointment, and feelings of being overwhelmed. Institutional factors included: inadequate high school preparation, loss of 
motivation to study due to program rigor, poor teaching/mentoring, inadequate advising, unwelcome culture of engineering department, financial pressures, poor academic performance, disinterested. ${ }^{4-6}$ The Introduction to Engineering course tries to integrate students into engineering as a whole, but the subcultures within individual engineering departments can help retain students.

A cultural analysis examined different engineering programs and found subcultures within engineering. ${ }^{7}$ These subcultures have been shown to affect women's choice of major. ${ }^{8}$

Additionally, this study showed that many students are not aware of industrial engineering when they are freshman, but migrate to industrial engineering later in their freshman, sophomore, and junior years. ${ }^{8}$

Orr, Brawner, Ohland, and Layton found that by semester eight, 90 percent of students are graduating in their current major. ${ }^{9}$ Many universities that have a first year program, require their students to be majored in "undesignated engineering" for their first quarter, semester, or year and this is where they found some significant differences: "Undesignated students... are more likely to choose electrical, civil, chemical, computer, aerospace, and agricultural/biological when they are required to take a course and more likely to choose industrial systems and mechanical engineering when they do not have to take a course [common first year engineering course]." (p. 23.1192.8). ${ }^{9}$ The researchers report that students that have a specific engineering major and take a common first year course in engineering have an 8 percent increased likelihood of staying in their major compared to students who do not take an introductory first-year course. ${ }^{9}$ This shows a benefit for students to be in the Introduction to Engineering course because it will increase the likelihood of them graduating by 8 percent after they have already chosen their major.

Another study showed that students' beliefs about enjoyment, importance, and usefulness in engineering decreased throughout their first year in engineering. ${ }^{5}$ This would affect students' choice of major because if they no longer enjoy it or cannot see the importance and usefulness of the major, and they may switch majors.

Ohland and Sill show that in their first year introduction to engineering course that both materials and ceramic, and industrial engineering would lose students without the benefit of those topics being introduced in their course. ${ }^{10}$ They also suggest that most of those students would have either tried to get into mechanical engineering or dropped out of engineering. ${ }^{10}$

These studies highlight the value of increased exposure to different engineering disciplines in an introductory engineering course on helping students in selection of major and retention.

\subsection{Theoretical Framework}

Expectancy-value theory was developed by Eccles and has been utilized within the engineering education community to explain achievement-related choices by expectations. ${ }^{11}$ There are four task-related values in expectancy-value theory: enjoyment value (interest), attainment value (personal identity), utility value (goal driven), and relative cost (effort, time, money). ${ }^{11}$ This theory has been used in studying engineering students. ${ }^{12-14}$ Although expectancy-value theory has been primary used to study engineering students and gender differences in values associated 
with career choices, this theory indicates that self-perceptions and inherent interests influence motivations of work in engineering. The researchers apply this theory to engineering students' choice of major.

\section{$\underline{\text { 2.0 Methods }}$}

\subsection{Department Presentations}

Presentations by the various engineering departments were held over two class periods. Seven engineering departments were represented: bioengineering, chemical engineering, civil engineering, computer engineering and computer science (one program), electrical and computer engineering, industrial engineering, and mechanical engineering. Each presentation lasted approximately 20 minutes. The time of each presentation was reduced this year (50 minutes in previous years) in an effort to increase engagement and interaction between students and department representatives. The reduction in time allowed students to attend multiple sessions in a single class period in smaller groups (approximately 15-30 students attended each presentation compared to approximately 100 in previous years). Additionally, students were given an assignment prior to the presentations as a primer to the various disciplines. In the assignment, students were provided links to short videos or web-based material on the various disciplines and asked to post a response to the following questions on an online discussion board:

1. What questions do you have for faculty and/or students in these disciplines? (This can be discipline-specific or general for all engineering disciplines)

2. What interests you most about each discipline?

3. What similarities and differences do you notice about the various disciplines?

Department faculty retained autonomy in developing their presentations, so there was no predetermined format. Some departments brought graduate and undergraduate students for a question and answer session. Some departments brought faculty and department heads that gave compelling presentations, and some brought demonstrations of projects students may work on in that discipline. The students selected two presentations to attend each class period, and thus were exposed to four department presentations of their choice.

\subsection{Company Panels}

Company panels were held later in the semester and took place outside of class time. Panels were held on six days over the course of three weeks; each session was one hour. Three or four companies attended each panel representing employers for a range of engineering disciplines. Students were required to attend at least two sessions (though they could attend all if desired). Thus, each student was exposed to 6-8 different companies that hire engineers from our university. The company representatives provided a brief overview of their company as well as a discussion of the type of work engineers do at that company and qualities they look for when hiring new co-ops/engineers.

\subsection{Assessment}


To evaluate student impressions of the department presentations and company panels, two surveys were provided to the students. The first was given to students within one week after the last department presentation and the second survey was given one week after the last company panel. Each survey contained seven questions related to the presentations and their choice of major with responses based on a five point Likert scale (strongly agree, agree, neither agree nor disagree, disagree, or strongly disagree). Additionally, each survey ended with an open response question asking whether the students would like to add any comments. Below are the questions from the first survey (the second survey used the exact same questions except the phrase "department presentations" was replaced with "company panels"):

1. The department presentations helped me make a decision about my choice of major.

2. The department presentations re-enforced my decision on choice of major.

3. I am reconsidering my choice of major after the department presentations.

4. Based on the information learned during department presentations, I have decided to change my major.

5. I feel confident in my decision of choice of major.

6. I am still undecided about my choice of major.

7. I have received enough information about the departments to make a decision about my choice of major.

The surveys were an assignment and part of students' course grade. However, points were given for completion only and were a minimal portion (4\%) of students' overall course grade.

Survey responses were assessed to determine the impact of department presentations and company panels on students' confidence in and decisions regarding selection of a particular engineering major. Additionally, student comments at the end of the survey were analyzed using constant comparative methods with open and axial coding and reviewed for further insight into student impressions of the activities.

\section{$\underline{\text { 3.0 Results and Discussion }}$}

\subsection{Department Presentation Survey}

Students completed an online survey after attending the department presentations (Table 1). There was an $82.9 \%$ completion rate for this survey. Over half (either strongly agree or agree) of the students reported that department presentations helped them make a decision about their choice of major. There were only nine percent (either disagree or strongly disagree) of students that did not think the department presentations were helpful in their choice of major. The department presentations had one-quarter of students reconsidering their major, but only 10 percent were actually in agreement to change their major. Seventy-seven percent of students reported feeling confident in their choice of major after department presentations.

Only 11 percent (strongly agree and agree) of students reported being undecided about their major and 69 percent reported disagreement (Table 1). 64 percent of students reported that they received enough information about the engineering disciplines after department presentations to make a decision about their major and 13 percent disagreed. 
Table 1. Results of student surveys following department presentations

\begin{tabular}{|l|c|c|c|c|c|c|}
\hline Question & $\begin{array}{c}\text { Strongly } \\
\text { Agree }\end{array}$ & Agree & $\begin{array}{c}\text { Neither } \\
\text { Agree nor } \\
\text { Disagree }\end{array}$ & Disagree & $\begin{array}{c}\text { Strongly } \\
\text { Disagree }\end{array}$ & $\begin{array}{c}\text { Not } \\
\text { Applicable }\end{array}$ \\
\hline $\begin{array}{l}\text { The department presentations helped } \\
\text { me make a decision about my choice } \\
\text { of major. }\end{array}$ & $12 \%$ & $43 \%$ & $26 \%$ & $7 \%$ & $2 \%$ & $10 \%$ \\
\hline $\begin{array}{l}\text { The department presentations re- } \\
\text { enforced my decision on choice of } \\
\text { major. }\end{array}$ & $29 \%$ & $43 \%$ & $17 \%$ & $6 \%$ & $2 \%$ & $3 \%$ \\
\hline $\begin{array}{l}\text { I am reconsidering my choice of } \\
\text { major after the department } \\
\text { presentations. }\end{array}$ & $7 \%$ & $18 \%$ & $19 \%$ & $31 \%$ & $21 \%$ & $4 \%$ \\
\hline $\begin{array}{l}\text { Based on the information learned } \\
\text { during department presentations, I } \\
\text { have decided to change my major. }\end{array}$ & $3 \%$ & $7 \%$ & $17 \%$ & $32 \%$ & $35 \%$ & $5 \%$ \\
\hline $\begin{array}{l}\text { I feel confident in my decision of } \\
\text { choice of major. }\end{array}$ & $31 \%$ & $46 \%$ & $14 \%$ & $6 \%$ & $1 \%$ & $1 \%$ \\
\hline $\begin{array}{l}\text { I am still undecided about my choice } \\
\text { of major. }\end{array}$ & $2 \%$ & $9 \%$ & $9 \%$ & $34 \%$ & $35 \%$ & $12 \%$ \\
\hline $\begin{array}{l}\text { I have received enough information } \\
\text { about the departments to make a } \\
\text { decision about my choice of major. }\end{array}$ & $17 \%$ & $47 \%$ & $18 \%$ & $10 \%$ & $3 \%$ & $5 \%$ \\
\hline
\end{tabular}

\subsection{Company Panel Survey}

Results of the survey following company panels are presented in Table 2. There was $77.6 \%$ a completion rate for this survey. The company panels had an overall agreement of 39 percent of helping students make a decision about their major, and 13 percent of students reported that company panels did not help them in their choice of major. Company panels re-enforced 64 percent of students' choice of major. There were 67 percent of students that overall disagreed with "reconsidering my choice of major" after the company panels and 75 percent disagreed with changing their major. Students reported confidence in their choice of major by 82 percent after the company panels. There were only three percent of students that disagreed with feeling confident in their choice of major. Students reported that they had received enough information to make a decision about their choice of major at 69 percent.

Table 2. Results of student surveys following company (employer) panels

\begin{tabular}{|l|c|c|c|c|c|c|}
\hline Question & $\begin{array}{c}\text { Strongly } \\
\text { Agree }\end{array}$ & Agree & $\begin{array}{c}\text { Neither } \\
\text { Agree nor } \\
\text { Disagre }\end{array}$ & Disagree & $\begin{array}{c}\text { Strongly } \\
\text { Disagree }\end{array}$ & $\begin{array}{c}\text { Not } \\
\text { Applicable }\end{array}$ \\
\hline $\begin{array}{l}\text { The employer panels helped me } \\
\text { make a decision about my choice of } \\
\text { major. }\end{array}$ & $9 \%$ & $29 \%$ & $40 \%$ & $9 \%$ & $3 \%$ & $9 \%$ \\
\hline
\end{tabular}




\begin{tabular}{|l|c|c|c|c|c|c|}
\hline $\begin{array}{l}\text { The employer panels re-enforced my } \\
\text { decision on choice of major. }\end{array}$ & $19 \%$ & $45 \%$ & $24 \%$ & $8 \%$ & $2 \%$ & $2 \%$ \\
\hline $\begin{array}{l}\text { I am reconsidering my choice of } \\
\text { major after the employer panels. }\end{array}$ & $5 \%$ & $10 \%$ & $17 \%$ & $39 \%$ & $28 \%$ & $2 \%$ \\
\hline $\begin{array}{l}\text { Based on the information learned } \\
\text { during employer panels, I have } \\
\text { decided to change my major. }\end{array}$ & $3 \%$ & $5 \%$ & $13 \%$ & $34 \%$ & $41 \%$ & $5 \%$ \\
\hline $\begin{array}{l}\text { I feel confident in my decision of } \\
\text { choice of major. }\end{array}$ & $30 \%$ & $52 \%$ & $14 \%$ & $3 \%$ & $0 \%$ & $1 \%$ \\
\hline $\begin{array}{l}\text { I am still undecided about my choice } \\
\text { of major. }\end{array}$ & $1 \%$ & $6 \%$ & $10 \%$ & $35 \%$ & $34 \%$ & $14 \%$ \\
\hline $\begin{array}{l}\text { I have received enough information } \\
\text { about the engineering disciplines to } \\
\text { make a decision about my choice of } \\
\text { major. }\end{array}$ & $20 \%$ & $49 \%$ & $20 \%$ & $7 \%$ & $1 \%$ & $3 \%$ \\
\hline
\end{tabular}

\subsection{Comparison of Department Presentations and Company Panels}

Over half (55 percent) of the students agreed that department presentations helped them make a decision about their major, but only 39 percent reported company panels helped. Four percent more students reported overall disagreement that company panels helped them make a decision on their choice of major compared to department presentations. Re-enforcement of students' choice of major was rated higher with department presentations than with company panels. Students reported that they disagreed with reconsidering their choice of major more with the company panels than with department presentations.

Company panels gave less reassurance of re-enforcing students' choice of major than department presentations, but more confidence in their decision. Following the company panels, $82 \%$ of students reported feeling confident in their choice of major and $69 \%$ reported that they had received enough information to make a decision, compared to $77 \%$ and $64 \%$, respectively, following department presentations.

Part of the decision process, if students had not already decided, is time. The department presentations came earlier in the semester by almost a month, and employer panels came in the middle of the semester, spread out over three weeks, ending after the student's final drop dates. As the students' progress through their first semester as engineering college students, they may feel more confident with the passage of time and the acknowledgement that they are passing the exams, quizzes, and homework. The lack of reconsidering their choice of major after the company panels may also have something to do time or that the students are confident enough about their choice that they no longer feel like they need to reconsider.

Overall, by the time the students attended the company panels they were more confident in their decision of major and felt that they had received enough information to make a decision, but did not report that company panels re-enforced their decision. The department presentations helped students make a decision about their major and re-enforced their decisions about choice of major.

Rodriguez-Simmonds, Ortega-Alvarez, Zahra Atiq, and Hoffmann (2015) show that direct interaction with engineers is highly influential in students' choice of major. From our data, 
exposure to employers of co-op students and engineers showed a five percent increase in students' confidence about their choice of major and that they had received enough information to make a decision about their major in engineering.

\subsection{Assessment of Survey Comments}

There were 236 comments on the department presentation survey. There were 209 comments on the company panel survey.

\subsubsection{Department Presentation Comments}

Overall, 69 percent of the comments about the department presentations were positive. The words and phrases used to determine if a comment was positive were: enjoyed, enjoyable, helpful, very informative, most interesting, better understanding, beneficial, helped a lot, liked, loved, nice to hear, great information, awesome job of presenting, and thanks for providing these department presentations.

Forty percent of comments contained negative statements. Some students made both positive and negative statements, thus it was coded as both positive and negative. Examples of negative coding consisted of words and phrases such as: more structured, wasn't all that interested, would have enjoyed discussion about jobs, need time for specific questions, liked there be more indepth discussions, rushed through presentations, more time, a little longer, too short, helpful if more students talked, not prepared for presentations, should have a power point, make these shorter.

Time. Time was mentioned in nine percent of the comments. The department presentations were supposed to last 20 minutes, so, in a 50 minute class, the students would be able to visit two presentations. Students chose which presentations to attend, thus forcing them to make decisions about what they might be interested in. This was done over two class periods. Almost all the of comments about time were negative, ranging from the presentations being too short (, or there wasn't enough time to answer questions or students felt rushed. One student seemed to enjoy the presentations but thought they should be longer, "It would have been helpful if the presentations were a little longer because some of the speakers had a lot of great info in their presentations but couldn't get through all of it because of the time constraints" (DP196). Some students wanted one-on-one time with the department presenters, "I have considered switching majors but they don't give you enough time to talk one on one to the presenters about what it mean(s) to switch or compare the 2 fields directly" (DP236). Although many of the negative comments about time were to make the presentations longer to allow more time with the presenters, there were a couple students that wanted to shorten the time, "Was there any way to make the presentations shorter... to allow for more presentations?” (DP174).

Style of Presentation. The style of presentation was left up to each department. The instructors encouraged the departments to bring upper classman or graduate students with them to the presentation to help answer questions. Many of the freshmen students had positive comments about the style of the presentations, 62 percent. There were 16 percent negative comments about the style of presentation. Students liked hearing from upper classman, "The presentations were a 
wonderful opportunity to learn how and why other students decided their major and what they are doing with it. My excitement for my department's presentation made me feel even more confident about my choice of major. It was especially helpful that several students from very different co-op backgrounds were present to represent the various applications of XXX engineering" (DP16). Some students felt pride and connection with their choice of major, "The XXX presentation helped me to see that it was the right choice for me. The presenters answered every question quickly and clearly. I left the presentation feeling great about my choice of major" (DP56). Some students did not like having only a Question and Answer session, "I wish they would've given more of a presentation rather than have the whole thing be question and answer" (DP20). Although the instructors recommended departments bring upper classmen to the presentations, the ultimate goal was to expose the students to as much information and people within each of the engineering departments so that students could identify a connection or something that helps them in choosing their major. For some students, the style of presentation, either using power point or having a question and answer session was important to them. Some students report having upper classmen answer questions was really helpful, but for others, they only wanted to hear from the department chairs. We know that exposing students to people in the different engineering fields is helpful, but the students seem to have individual preferences.

Structure of Department Presentations. Seventeen percent of the comments were negative about the structure of department presentations. One student commented positively about the structure of the presentations, which was less than one percent. Many of the negative comments stated that they wanted to see all the presentations, "If we had the opportunity to get to hear a presentation from every single department instead of just two out of three, I would feel like I would have a better idea of what each major does" (DP225).

Many students had short comments saying "Very helpful" or "They did a good job" which were classified as positive feedback but it did not give the instructors a lot of insight as to what the students really liked or thought about the experience. Overall, the feedback was positive and it seemed that most students thought department presentations were a vital part of the class for them to learn more about engineering.

\subsubsection{Company Panel Comments}

The company panels occurred almost one month later than department presentations. Overall, the comments were 65 percent positive and 35 percent negative. The words and phrases used to determine that the comment was positive: great, very helpful, informative, very informative, excited, insightful, enjoyed, helped, great presentations, lucky to attend, really good, being able to learn, I feel confident in my major now, helped. The words and phrases used to code the negative comments were: severely underrepresented (major choice), wasn't enough talking about XXX(specific major), didn't like, didn't go into as much depth, sad, none (company panels) interested me, did not show up, more engineers and less HR (human resources).

Majors Represented. The instructors worked with the director of the Engineering Co-op and Career Development Office to have each major represented at the company panels. Two (of the 24 invited) companies could not make it on their day, either the person that was supposed to 
come was sick or something happened, where those majors were without representation. This was the most common overall negative feedback received, 23 percent. Nine percent of the overall comments were positive about a specific major represented. Students reported, "Unfortunately, none of the panels I went to had a significant focus on XXX" (CP209). And another student wrote, "The two panels I signed up for promised to have XXX employers. One said employer didn't show up and the other made no mention of XXX during the presentation. Unfortunately, I didn't learn anything about potential employers for my major because of this" (CP194). Prior to the company panels, the co-op director had given a presentation to students in Introduction to Engineering. In this presentation, he mentioned one major (bioengineering) that is harder to find co-ops for than others (especially locally), and similarly it has been harder for these majors to find jobs after graduation. Likewise, we had fewer representatives for bioengineering at the company panels. Thus, there was feedback about the lack of representatives for this bioengineering, also. One student commented, "I would have liked for there to be more companies that hired $X X X$ " (CP100).

Co-op and Careers. This university has a mandatory co-op program for all the engineering students. Most students spend three semesters in co-op before graduation. Thirty percent of students wrote positive comments mentioning co-ops or future jobs, and 13 percent wrote something negative. One positive comment from a student about how the company panels helped them consider their future, "The employer [company] panels were really helpful because they gave me a look into what I could potentially be doing for the rest of my life, as well as in a year when I have to think about co-ops" (CP158). The researchers had hoped that the students would be able to tie together that their choice of major directly impacts their co-op and job prospects when they graduate, but some students did not give feedback in correlation with their major choice, as one student commented, "These panels helped me more with co-op decisions than decisions about my major" (CP201) and "These panels made me more excited about doing coops. At first I thought the co-ops would be a boring job just doing busy work like an internship, but the panels showed otherwise" (CP199).

Switching Majors. Fifteen percent of students had positive comments about students' major, either saying that they were switching or staying based on the company panel experience. Five percent of students had negative comments. There were a few students that commented on switching majors because of the company panels. A student explained, "The only thing that kind of makes me reconsider my major is the fact that one guy said he didn't want to sit at a desk all day doing engineer work. This kind of makes me want to look into other options about what I can do with my engineering degree to do more hands on work and on-site work" (CP176). Another student wrote, "The presentations were an excellent way to learn about what different engineers actually do after graduation and while on co-op. Most probably assume that XXX (major) will work at XXX or something similar, and while that is probably common the presentations show that there are other uses for XXX (major) besides a utility company. I really enjoyed the [company] presentation, and would enjoy doing something that I could see and know has a different effect on people. While I'm probably not going to switch to XXX due to all of the medical classes, it has given me something to think about and research to make a better decision. Prior to the presentations I was pretty confident XXX was the best choice for me due to 
past experience, but I can see there is more out there, and could see myself doing something different" (CP188).

Some students commented that the company panels helped them be more confident in their choice of major, as this student explained, "Right before the panels began I switched from XXX engineering to XXX engineering. I was still a little weary of my choice, but after hearing several of the medical device companies say they were mostly looking for XXX engineers I felt more secure in my choice of XXX engineering. The panels were really helpful and I also enjoyed hearing about all of the job opportunities" (CP146). One student said, "Made me never want to go in to XXX engineering" (CP122).

The company panels helped students meet employers that hire engineers in their major and gave the students another avenue to hear from an engineer in their choice of major and ask them questions. Overwhelmingly, there was positive feedback about the company panels. Students commented more on their choice of major, either feeling more confident or switching in the company panel survey then in the department survey.

\section{$\underline{4.0 \text { Conclusions }}$}

In this study, two activities in an Introduction to Engineering course were assessed for their impact on students' decisions regarding their choice of major. Presentations by engineering departments at our university and panels of engineering employers were added to the course in Fall 2015 with the goal of increasing first-year students' knowledge about the various engineering disciplines to help them make a more informed major choice early in their academic careers.

Student impressions of the activities were assessed through online surveys. Results indicate that both activities, department presentations and company panels, were viewed positively by a majority of students. The department presentations (early in the semester) particularly helped students make a decision about their major. Though company panels appeared less effective (a lower percentage of students felt these helped them decide on a major), the decrease could simply be due to the fact that these came later in the semester and a majority of students had already made up their mind about which major to pursue. Additionally, students' confidence increased in their choice of major suggesting that the company panels were effective.

Survey comments provided specific feedback regarding which aspects of the activities students found most helpful and insight into changes that might improve the activities in future semesters. For example, it is important to these students to interact with and hear from all engineering disciplines.

Though both department presentations and company panels generally were viewed positively by students, future research is needed to understanding why students choose different majors or what factors specifically contribute to their choices. Additionally, future work will investigate whether the added course activities actually reduce the number of students who change majors after their first year. Survey results are only indicative of student impressions; it will be valuable to examine whether these activities have a measurable effect. Furthermore, future work should 
look at how time affects students' choice of major at the university. Do students feel that they need to make a decision quickly or that they have a lot of time to decide? Do students understand the that there may be some unintended wasted credit hours by switching their major, which is why it may be important to make an informed decision within the first year? Additional research into these areas may help faculty tailor the first-year curriculum to provide the most benefit to students and improve retention efforts.

\section{References}

1. Argrow, B. M., Louie, B., Knight, D. W., Canney, N. E., Brown, S., Blanford, A. J., Gibson, C. L., \& Kenney, E. D. (2012). Introduction to Engineering: Preparing First-Year Students for an Informed Major Choice. American Society for Engineering Education Annual Conference. San Antonio, TX.

2. Zahorian, S., Elmore, M., \& Temkin, K. (2013). Factors that Influence Engineering Freshman to Choose Their Engineering Major. American Society for Engineering Education Annual Conference. Atlanta, GA.

3. Rodriguez-Simmonds, H. E., Ortega-Alvarez, J. D., Atiq, S. Z., \& Hoffmann, S. R. (2015). Identifying Sources of Information that Students use in Deciding which Engineering Major to Pursue. American Society for Engineering Education Annual Conference. Seattle, WA.

4. Moakler, M. W., \& Kim, M. M. (2014). College Major Choice in STEM: Revisiting Confidence and Demographic Factors. The Career Development Quarterly, 62(2), 128-142.

5. Jones, B. D., Paretti, M. C., Hein, S. F., \& Knott, T. W. (2010). An Analysis of Motivation Constructs with First-Year Engineering Students: Relationships Among Expectancies, Values, Achievement, and Career Plans. Journal of Engineering Education, 99(4), 319-336.

6. Meyer, M., \& Marx, S. (2014). Engineering dropouts: A qualitative examination of why undergraduates leave engineering. Journal of Engineering Education, 103(4), 525-548.

7. Godfrey, E. (2007). Cultures within cultures: Welcoming or unwelcoming for women. In Proceedings of 2007 of American Society for Engineering Education. Honolulu, HI.

8. Brawner, C. E., Camacho, M. M., Lord, S. M., Long, R. A., \& Ohland, M. W. (2012). Women in Industrial Engineering: Stereotypes, persistence, and perspectives. Journal of Engineering Education, 101(2), $288-318$.

9. Orr, M. K., Brawner, C. E., Ohland, M. W., \& Layton, R. A. (2013). The Effect of Required Introduction to Engineering Courses on Retention and Major Selection. American Society for Engineering Education Annual Conference, Atlanta, GA. (p. 23.1192.8).

10. Ohland, M. W., \& Sill, B. L. (2002). Communicating the impact of an introduction to engineering course to engineering departments. In Frontiers in Education Annual Conference. Boston, MA. (p. F3B-17).

11. Eccles, J. S. (1994). Understanding women's educational and occupational choices. Psychology of women quarterly, 18(4), 585-609.

12. Matusovich, H. M., Streveler, R. A., \& Miller, R. L. (2010). Why do students choose engineering? A qualitative, longitudinal investigation of students' motivational values. Journal of Engineering Education, 99(4), 289-303.

13. McGrath, C., Gipson, K., Pierrakos, O., Nagel, R., Pappas, J., \& Peterson, M. (2013, October). An evaluation of freshman engineering persistence using Expectancy-Value Theory. Frontiers in Education Annual Conference. Oklahoma City, OK. (p. 1644-1650).

14. Jones, B. D., Paretti, M. C., Hein, S. F., \& Knott, T. W. (2010). An Analysis of Motivation Constructs with First-Year Engineering Students: Relationships Among Expectancies, Values, Achievement, and Career Plans. Journal of Engineering Education, 99(4), 319-336. 